\title{
Mutações do trabalho e experiência urbana
}

\author{
Vera da Silva Telles
}

Já não é de hoje que se discutem os efeitos excludentes das atuais mutações do trabal ho, sob o impacto da reestruturação produtiva em tempos de revolução tecnológica e globalização da economia. N o entanto, ainda pouco se sabe sobre as configurações societárias que vêm sendo urdidas nas dobras dessas transformações. Entre, de um lado, os artefatos da "cidade global" sob o foco dos debates entre urbanistas e pesqui sadores da economia urbana e, de outro, os "pobres" e "excluídos" tipificados como público-alvo das políticas ditas de inserção social, há todo um entramado social que resta conhecer. E éisso justamente que situa o terreno em que ganha pertinência relançar a discussão sobre os sentidos e os lugares do trabal ho na tessitura do mundo social. Seo trabal ho não mais estrutura as promessas de progresso social, se os coletivos "de classe" foram desfeitos sob as injunções do trabalho precário, se direitos esindicatos não mais operam como referências para as maiorias, se tudo isso mostra que os "tempos fordistas" já se foram, o trabal ho não deixa de ser uma dimensão estruturante da vida social.

M as éisso também que abrea interrogação sobre as novas configurações sociais nas quais essa experiência se processa. $\mathrm{N}$ ão se trata tão-somente da ampliação do mercado informal e do aumento das hostes dos excluídos do mercado detrabal ho. Como mostra Francisco de O liveira (2003), a chamada flexibilização do contrato de trabal ho significa que o trabal ho "sem forma" se expande no núcleo do que antes era chamado de "mercado organiza- 
do". N a base desse processo, diz 0 autor, está o salto nas alturas da produtividade do trabal ho em época de revolução tecnológica e financeirização da economia, de tal modo que o processo de valorização se descola dos dispositivos do trabal ho concreto etermina por implodir as distinções entretempo do trabalho e tempo do não-trabalho, entre emprego e desemprego. É o trabal ho abstrato levado a extremos, que captura, mobiliza e transforma processos sociais e atividades as mais disparatadas em sobreval or. Q uebra-se o vínculo entre trabalho, empresa e produção da riqueza, e são outros os agenciamentos e diagramas de relações que se constituem. Zarifian (2003) fala de uma "economia de serviços", que não diz respeito às divisões conhecidas de setores de produção e que, a rigor, as torna irrelevantes, pois tem a ver com a trama de relações materiais e imateriais entre produção e consumo - publicidade, efeitos de marca, ações de marketing, cartões de fidelidade, etudo o mais que acompanha o produto ou o serviço vendido/consumido, detal forma que os consumidores terminam por participar da formação do valor apesar de não serem contabilizados como tal. 0 utros vão lançar mão da noção de "trabalho imaterial" para discutir atividades que não são codificadas como trabal ho, que tentam fixar normas culturais, modas, gostos e padrões de consumo (cf. Lazzarato, 2002) ou que capturam e organizam os "tempos da vida" e não apenas os "tempos do trabalho" (cf. Aspe et al., 1996), tornando cada vez mais difícil diferenciar tempo do trabalho e tempo da reprodução.

São mutações defundo. M as então épreciso reconhecer queisso altera as relações entretrabal ho esociedade, sejano registro do trabal ho quesedescola dos dispositivos do emprego para se desdobrar nas formas variadas de trabaIho precário, intermitente, descontínuo, eque tornam inoperantes as diferenças entre o formal eo informal; sejano registro das miríades de expedientes de sobrevivência que mobilizam os "sobrantes" do mercado detrabalho, mas que também operam como outros tantos circuitos por onde a riqueza social globalizadacircula eproduz valor, tornando igualmenteindiscerníveis as diferenças entre emprego e desemprego, entretrabal ho enão-trabal ho. É uma situação que está a exigir um giro em nossas categorias, demodo a construir um plano de referência que permita colocar em perspectiva e figurar esses processos, ressituar os problemas, levantar outros tantos e perceber nas dobras das redefinições e desagregações do "mundo fordista" outros diagramas de relações, campos de força que também circunscrevem os pontos de tensão, resistências ou linhas defuga pel as quais perceber a pul sação do mundo social. 
Por outro lado, esse constante entra-e-sai do mercado em meio aos diversos expedientes de trabalho precário termina por alterar as referências que pautavam e ritmavam a vida social. Se éverdade quea desconexão entre trabalho e empresa já faz parte da paisagem social, isso também significa que os tempos da vida e os tempos do trabalho tendem a se articular sob novas formas não mais contidas nas relações que antes articulavam emprego e moradia, trabalho e família, trabalho e não-trabalho (cf. Bessin, 1999). Eram binaridades que pautavam os ritmos da vida social, tendo por referência as regularidades e os disciplinamentos impostos pelas formas de empre go (cf. Supiot, 1994; 1999). M as será necessário então se desvencilhar dessas binaridades clássicas, assim como a de formal-informal, para apreender a nervura própria do campo social, que não se deixaria ver se nos mantivéssemos presos a elas na análise do trabalho e do urbano.

Essas questões exigiriam uma discussão mais acurada, impossível de de senvolver nos limites deste artigo. Porém, servem como indicação de que talvez tenhamos que mudar o foco das atenções. Talvez seja preciso um deslocamento do jogo de referências para ressituar o trabalho no mundo social. $\mathrm{N}$ ão tanto as verticalidades que construíram o trabal ho nas formas conhecidas (e suas regulações centralizadas), mas os vetores horizontalizados de relações que articulam trabal ho, a cidade e seus espaços, outros agenciamentos sociais e também outros eixos em torno dos quais desigual dades, controles e dominação se processam, afetam formas de vida e os sentidos da vida (cf. Zarifian, 2000).

Também é o caso de se perguntar de que modo as novas realidades do trabalho (e do não-trabalho) redesenham mundos sociais, as relações de força e campos de práticas que fazem a tessitura da ci dade e seus espaços ${ }^{1}$. Ainda: de que modo são redefinidas práticas sociais e as mediações que conformam uma experiência social sob outro diagrama de relações e outro jogo de referências. As circunstâncias variadas do trabal ho precário e intermitenteredefinem tempose espaços da experiência social (cf. Sennet, 2000). Alteram, poderíamos dizer, a própria experiência urbana, seguindo os circuitos descentrados dos “territórios da precariedade” (cf. LeM archand, 2004).

Talvez seja então o caso de prospectar os pontos de clivagem dessas novas realidades seguindo as práticas (esuas mediações) nesses circuitos redefinidos do mundo social. Pontos de clivagem que podem ser apreendidos justamente nos deslocamentos da experiência social e que cavam fundo a dife rença entre as gerações. E essa pode ser uma via de entrada para a descrição desse mundo social redefinido. Afinal, a diferença entre as gerações tem
1. Essas questões estão no centro de uma pesquisasobretrajetóriasurbanas na cidade deSão Paulo, desenvolvida sob coordenação partilhada com Robert $C$ abanes (IRD -França), nostermos de um convênio CNPq-IRD (20032006). Também contou com apoio do CN Pq e da Fapesp. Este artigo apóia-se em resultados dessa pesquisa. A respeito, ver Tellese C abanes (2006). 
atual mente a peculiaridade histórica de coincidir com mudanças de fundo no mundo do trabalho e nas dinâmicas urbanas.

Trabalho e cidade: relações redefinidas

Sabe-se que sobre os mais jovens recai todo o peso do desemprego e do trabalho precário. Em torno de suas figuras entrecruzam-se os fios de um mundo social que se vem desenhando nas dobras do "mundo fordista" em dissolução (cf. Beaud e Pialoux, 2003). Justamente por isso são as novas gerações as que abrem uma senda para compreender as mutações do trabaIho e de seus significados.

A diferença das gerações é, portanto, algo que precisa ser bem entendido, não para fazer a comparação ponto a ponto (era assim, não é mais), que sempre contém o risco de uma descrição em negativo quetermina por falar sempre do mesmo (o trabal ho fordista), apenas com os sinais invertidos. 0 problema aí não é tanto a idealização de algo que, ao menos no caso brasileiro, não tem por que ser celebrado (essa é a crítica mais fácil de se fazer, eque já foi feita por muitos), mas ficar aprisionado num jogo de referências que não permite apreender os sentidos da experiência social que se vem desenhando. E isso exige um trabalho de deciframento do social capaz de captar novos campos de força configurados sob outro diagrama de relações e referências sociais. Para os mais jovens, as circunstâncias atuais do mercado de trabalho não significam uma degradação de condições melhores ou mais promissoras em outros tempos. Eles entraram num mundo já revirado, em que o trabalho precário e o desemprego já compõem um estado de coisas com o qual têm que lidar, e estruturam 0 solo de uma experiência em tudo diferente da geração anterior. Por outro lado, entram na vida adulta em uma cidade inimaginável para as gerações anteriores. Ponto e contraponto de uma mesma real idade, os capitais globalizados transbordam as muito ricas e modernas fortalezas globais dos serviços de ponta, e fazem expandir os circuitos do consumo de bens materiais e simbólicos que atingem os mercados populares. São fluxos socioeconômicos poderosos que redesenham os espaços urbanos, redefinem as dinâmicas locais, redistribuem bloqueios e possibilidades, criam novas clivagens e afetam a economia doméstica, provocando mudanças importantes nas dinâmicas familiares, nas formas de sociabilidade e redes sociais, nas práticas urbanas e seus circuitos. É também por lá que se encontram os novos e excludentes empregos, no mais das vezes intermediados 
por agências de trabalho temporário, que vão mobilizando, entre os circuitos urbanos locais, os operadores de caixas registradoras, balconistas, porteiros, faxineiras, empregados para serviços variados.

0 fato éque, em uma grande cidade como São Paulo (e, podemos supor, também em outras metrópoles), ao perseguir os trajetos e percursos dos mais jovens (entre 20 e 30 anos, pouco mais, pouco menos), vai se desenhando o perfil de uma cidade também ela muito alterada em relação às décadas anteriores (cf. Telles e C abanes, 2006). 0 u melhor: esse é um ângulo pelo qual a cidade vai se perfilando com todas as ambivalências e as complicações que recobrem os tempos atuais.

Em que pese tudo o que se tem dito sobre fragmentação urbana e dual ização social, esses circuitos global izados operam como importantes pólos de gravitação para as novas gerações. Portanto, será preciso levar a sério a sugestão de Saskia Sassen (1998), de queentender as novas realidades urbanas exigequese desvencilhe do quea autora define como "narrativa da exclusão": uma descrição das cidades globais - ou dos espaços globalizados- que tem como única referência os winners dos altos circuitos do capital. N ão por acaso, valelembrar, no mesmo passo em queesses equipamentosseespal ham pela cidade, também vai se proliferando o igualmentemuitíssimo moderno trabal ho temporário, mediado por agências deemprego conectadas a empresasterceirizadas de prestação deserviços. É também por essescircuitosqueos mais jovens fazem seus percursos, sempre descontínuos e sempre instáveis, no mercado de trabal ho. E realizam uma experiência da cidade tensionada entrea brutalidade das desigual dades e a sedução encantatória do moderno mercado deconsumo, em um jogo ambivalentedepossibilidadesebloqueios para o acesso a uma vida urbana ampliada.

Eis o ponto que traz as novas gerações para o centro nevrálgico desse mundo social quese vem configurando. São jovens que se lançam no mundo no momento em que o encolhimento dos empregos e a precarização do trabalho acontecem simultaneamente e no mesmo passo da ampliação e diversificação dos circuitos da vida urbana.

M asisso nosabreoutro feixedequestões. $N$ essemundo social redefinido, a experiência do trabal ho (e do não-trabalho) entrelaça-se, ou mesmo confunde-se, arriscaríamos dizer, com a experiência da própria cidade. É o caso de se interrogar pelas referências por meio das quais a experiência das desigual dades vem seprocessando, junto com a vivência dos bloqueiosa possibilidades de vida em um tempo que celebra o desempenho, a performance e 0 sucesso como medidas (aliásinefáveis) deautonomia individual².
2. Como bem nota Eheremberg (1991), a autonomia não é mais pensada como recusa às subordinações de um mundo disciplinar (ver osmovimentosculturais dosanosde 1960), mas é agora figurada à imagem e semelhança da empresa, eo seu princípio éa concorrênciaea competição. Da atual celebração do esporte transformado em espetáculo demassaà proje ção do empresário bemsucedido (aliás, também mediatizado etransformado em cel ebridade) como padrão moral a ser seguido, passando pelo consumo, são essas as figuras do "novo individualismo" que se vêm configurando desde meados dos anos de 1980. 
M as, se é assim, será importante então escapar dessa clivagem, que atravessa o debate contemporâneo, entre, de um lado, a economia urbana e os artefatos da "cidadeglobal" e, de outro, a "exclusão social" e osterritórios da pobreza. 0 que se trata de ver aqui são as relações entre cidade e trabal ho. Relações que não podem mais ser consideradas nos termos do debate dos anos de 1980, mas que, por isso mesmo, precisam ser reelaboradas se quisermos escapar de uma visão empobrecida do mundo social reduzido às suas supostas binaridades.

N ão se quer, que se diga desde logo, contrapor à "cidade dos muros" para lembrar a expressão cunhada por Teresa C aldeira (2000) - uma suposta (e falsa) democratização da "nova sociedade do consumo". A questão é outra. 0 que estamos aqui sugerindo é outro modo de figurar e descrever esse mundo social. Para isso será preciso também ressituar o lugar dos grandes equipamentos de consumo em um mundo atravessado pelos circuitos globalizados do capital, e tomá-los por aquilo que são no movimento mesmo de val orização do capital. Pois nesses tempos globalizados, seguindo os movimentos acelerados de desterritorialização do capital, a riqueza social mobiliza os "artefatos urbanos" (cf. H arvey, 1996) e agencia os espaços da cidade, pedaços globalizados que recortam o mundo urbano, articulando ritmos de consumo e modos de vida com os fluxos da produção e dos capitais (cf. Veltz, 1996), no mesmo passo em que se vai ampliando a inadimplência generalizada. $Q$ ualquer um que circule pel os bairros das periferias mais pobres haverá deencontrar a parafernália do consumo moderno epósmoderno, e haverá de encontrar o morador pobre desses lugares mais-doque-pobres exibindo, junto com a fatura de uma dívida sempre adiada, as versões populares (ou nem tanto) dos cartões de crédito que também chegaram por lá: éa financeirização do popular fiado. Eis aí os "sujeitos monetários sem mercado", para usar a expressão cunhada por Kurz (1992), ou o "homem endividado", essa figura da "sociedade do controle", como diz D eleuze (1992), que vem substituindo o "homem confinado" da sociedade disciplinar descrita por Foucault.

É bem verdade, diz ainda D eleuze (1992, p. 224), que o capitalismo mantém em escal assemprecrescentesa extrema miséria das maiorias, povose populações "pobres demais para a dívida, numerosos demais para o confinamento: 0 controle não só terá que enfrentar a dissipação das fronteiras, mas também a explosão dos guetos e favelas". M as, para usar a linguagem do filósofo, os "fluxosurbanos" liberados pela subtração dos dispositivos do trabalho circulam evão encontrando outrosagenciamentose pontos de cristali- 
zação, de que é evidência esse promissor e expansivo mercado representado pelo tráfico de drogas e pelas redes do crime organizado, aliás também eles globalizados e conectados aos circuitos desterritorializados do capital financeiro. $\mathrm{N}$ ada mais eloqüente do que o retrato desenhado por Alba Zaluar (1996, p. 55) deum garoto metido no tráfico de drogas no Rio de Janeiro: "com umaAR-15 ou metralhadora U ZI, consideradas símbolos desuavirilidadeea fontedegrandepoder local, com um bonéinspirado no movimento negro daAmérica do $\mathrm{N}$ orte, ouvindo músicafunk, cheirando cocaína produzidana Colômbia, ansiando por um tênisN ike do último tipo eum carro do ano". Isso não seexplica, dizZaluar, ecom razão, pelos níveis desalário mínimo ou pelo desemprego: "entender como o ilícito eo ilegal se enraizaram no setor informal paracomandar um exército de desempregadosesóciosmenoreséfundamental", atéporquetudo isso põeem movimento bensmateriaise monetários que entram na circulação demercadorias do mundo capitalista.

Entre a destituição dos miseráveis e os brilhos faiscantes desse capitalismo pós-moderno, entre o futuro sempre adiado (como a dívida, deixada para o dia seguinte) e o também muito pós-moderno presente imediato do garoto do tráfico, em quetudo isso se conjuga no verso-e-reverso do capitalismo contemporâneo, há todo um entramado de linhas que se cruzam e entrelaçam, e vão montando um sociusque ainda será preciso conhecer meIhor. E éa própria experiência das novas gerações e seus circuitos, no nervo exposto das complicações atuais, que nos dá as pistas para tentar outra descrição do mundo social.

\section{Personagens urbanos e seus percursos}

É sob essa perspectiva que tratamos de seguir os percursos dessas novas gerações. São situações traçadas pel os circuitos das trajetórias de seus personagens. Personagens urbanos, podemos dizer. Em seus contextos de referência, essas trajetórias operam como prismas pelos quais o mundo urbano vai ganhando forma em suas diferentes modulações. São esses personagens quetornam práticas urbanas e vetores policentrados perceptíveis, em torno dos quais esse mundo social vem se desenhando (cf. Telles, 2006).

São experiências que se desenrolam em uma região situada na periferia sul da cidade de São Paulo, eque começou a se expandir a partir dos anos de 1970, acompanhando os fluxos dos empregos industriais. N essa região, quefoi o pólo industrial da "cidade fordista", são nítidos os sinais da reconversão produtiva, bem como as recomposições urbano-espaciais da década 
de 1990, sob o impacto do muito próximo e rico quadrante da modernização globalizada da cidade. Aqui, os fluxos da riqueza e da pobreza se tangenciam o tempo todo, entrecruzam-senos equipamentos de consumo que atravessam a região e nessa mistura especial de legal e ilegal, regular e irre gular, lícito e ilícito de que são feitos os circuitos dos empregos que, a partir do pólo moderno-moderníssimo da economia, vão se espalhando pelas re des de subcontratação e trabal ho precário.

A viradadostempos está cifrada nasinflexõesenas circunstâncias devida dosque, tendo chegado a São Paulo nosanos de 1970 ou no início dos 1980, fizeram um percurso pelos empregos fabris, chegaram às então distantes e desoladas periferias da cidade, real izaram o "sonho da casa própria" pelas vias da autoconstrução da moradia, seviram às voltas com loteamentos clandestinos e se envolveram nas lutas sociais do período. 0 u então se instalaram precariamente no que haveria de se transformar, vinte anos depois, em uma grandefavela, naqual, ecomo contraponto da épica dos movimentos sociais, o clientelismo vel ho deguerrasefaz presenteeoperantenas dobraseredobras das muitasilegalidades dequeéfeito o mundo social.

Para essas famílias, a diferença dos tempos coincide com a diferença das gerações e são sobretudo os jovens personagens dessas histórias que podem informar-nosal guma coisa sobre os vetores eas linhas deforça que deslocam os pólos de gravitação da geração anterior (entre o trabalho e as melhorias urbanas locais), e redefinem campos sociais. Seguindo as trilhas dos mais jovensvão sedelinean do os perfisambivalentes da modernidadeglobalizada: uma experiência social que se configura nos limiares e nas passagens entre mundos distintos, entreo universo empobrecido da periferia e os shoppings centers, os lugares prestigiosos de consumo e lazer (referências urbanas inescapáveis para essa geração), osbaixosempregos do terciário moderno eos circuitos do trabalho precário quetangenciam osfluxos da riqueza plasmados nos espaços urbanos. São esses limiares e essas passagens (e seus bloqueios) que precisam ser bem compreendidosebem situados, poiséaqui quesearma uma teia de relações (etensões) quevia de regra escapa às definições modelaresde exclusão social ou segregação urbana.

São esses percursos, da segunda ou terceira geração, que nos fazem perceber as conexões entre trabalho eexperiência urbana. $N$ ão mais as referências que ordenavam a experiência social dos tempos do "trabalho fordista" da primeira geração. $\mathrm{N}$ ão mais as mediações do trabalho regulado, dos direitos trabal histas e sindicatos, que ritmavam os tempos da vida e os articulavam com os tempos políticos da cidade. M as nem por isso o trabalho, 
mesmo precário e descontínuo, incerto e de futuro mais incerto ainda, deixa de ser um poderoso conector com o mundo social. 0 utra experiência de trabal ho, outra experiência urbana. 0 utro diagrama de referências e relações que redefine os agenciamentos da vida edas formas de vida, enos quais e pelos quais é possível apreender a nervura própria desse campo social redefinido.

\section{Maurício e Nair, os jovens empreendedores: nos circuitos faiscantes dos serviços globalizados}

M aurício (20 anos) e N air (17 anos) ${ }^{3}$ compõem a terceira geração de uma família de operários. M igrante do Paraná, o patriarca $G$ enésio chegou a São Paulo em 1978 (tinha então 45 anos) com a esposa e seis filhos. Alguns dias depois já estava instalado em uma moradia mais do que precária em uma região de ocupação, que, no correr dos anos, transformou-seem uma grande favela. É uma família de operários metalúrgicos. G enésio, hoje aposentado, conseguiu emprego poucos dias depois de sua chegada, e se guiu por dezenove anos nesse mesmo emprego. Q uanto aos cinco filhos mais velhos, em pouco tempo também estavam trabalhando em algumas das grandes fábricas da região. D epois, ainda nos anos de 1980, passariam a trabal har nas pequenas fábricas instaladas nas imediações da favela, elá se manteriam por todos esses anos, com salários baixíssimos, mas uma estabilidade que as novas gerações já não iriam conhecer.

O sjovens $M$ aurício eN air estão tentando a sortenos circuitosfaiscantes dos serviços globalizados. M aurício começou a trabalhar em 1999. Tinha então 16 anos e conseguiu, por indicação de conhecidos de seus pais, um emprego de office-boy no ParqueAquático T heW Waves. Seis meses depois, 0 parquefoi àfalência efechou. $\mathrm{N}$ o seu lugar foi construído um hipermercado Extrae, ao lado, uma das maiores emais sofisticadas academias deginástica, a caríssima U nysis. D epois, trabal hou como office boy numa agência deemprego, na qual progrediu para auxiliar administrativo. M as a quantidade de serviço diminuiu e a empresa se afundou em dificuldades financeiras. Ele amargou doisanos de desemprego, com inúmeras epersistentestentativas de achar trabalho, sem sucesso. Q uase sempre em lojas de shoppings centers, al gumas degrifesfamosas: “Eu queriatrabal har com o público, éisso o queeu gosto, edaí falei - 'vou medar bem'". Fez entrevistanaEllus, grifeconhecida de jeans, mas a concorrência era muito grande - "todo mundo querendo entrar, pessoal quetrabal ha, pessoal que estava cursando faculdade, tinhaaté
3. Assim como para os outros personagens apresentados a seguir, essas informações referem-seao ano de2001, momento em queasentrevistas foram realizadas. 
modelo, sabe?". Espal hava currícul ospor ondepassava, sem conseguir nada. Então surge a oportunidade, quando uma vizinha o apresenta para a assessora de imprensa de um escritório de promoção de eventos culturais. A empresa fica no rico bairro do M orumbi, na avenida Giovanni G ronchi. 0 seu trabaIho é atender os telefonemas, cuidar das agendas, marcar entrevistas. Esse emprego joga $M$ aurício em um mundo queseria inimaginável para seuspais. Vez por outra, acompanha os eventos organizados, por exemplo, no 0 lympia, badalada e prestigiosa sala de shows. M aurício transita pelo "circuito nobre" da cidade: shoppings centers, baresepontos deencontro no C entro, ou os agitadíssimos bairros de classe média, M oema eV ila N ova C oncei ção, PinheiroseV ilaM adalena. D iz quecomeçou atransitar peloscircuitos badalados já nos tempos da agência deempregos: fez amigos, passou afreqüentar outros circuitos, conheceu muita gente e vez por outra conseguia entrar de graça nas grandes casas de espetáculo, pelas mãos de "gente conhecida" lá de dentro. "Tenho amigos deSão Paulo inteiro", diz M aurício.

É bem possível que o rapaz exagere ehaja um tanto de ficção nisso tudo. $M$ as o fato é que o rapaz já está mirando para outros lugares e de outros lugares. Sonha fazer uma "faculdade de comunicação" e encontrar o seu lugar nesses faiscantes circuitos dos modernos serviços da "cidade global". Acha que tem jeito e talento para isso. É muito provável que esse sonho dourado não vá longe e que o rapaz logo bata de frente nas regras mais do que excludentes dos modernos-moderníssimos circuitos globalizados. M as os lances da vida já configuraram outro jogo de referências eoutros prismas pelos quais a cidade se Ihe apresenta: diferente da geração dos seus pais, que val orizam exatamente essa espécie de "mundo à mão" que a favela lhes oferece - a família que está por perto, os empregos ali do lado. Para M aurício, na favela tudo élonge e a periferia não tem nada, os lugares são perigosose, além do mais, étudo muito feio: "Aqui não tem nada, não tem nem paisagem agradável para ver".

N air, 17 anos, primade M aurício, começou a trabal har muito cedo eseus percursos dizem algo dos novos circuitos dos empregos da região. Em 1995, aos 11 anos de idade, trabalhava em uma pequena firma terceirizada que montava brinquedos para o M cD onald's. Várias meninas suas vizinhastrabaIhavam lá. Q uem tocava o negócio era uma conhecida dafamília, na garagem de uma casa em uma rua próxima à avenida Giovanni G ronchi, ponto de ligação entrea pauperizada região em quemoraeo riquíssimo M orumbi. N o seu entroncamento, ao lado do hipermercado C arrefour, está a loja do M cD onald's. Em 1998, trabal hou seis meses numa empresa que monta ca- 
netas para propaganda: era ano eleitoral e havia muito serviço. D epois, em um período em quenão conseguia nenhum emprego, resolveu montar, junto com a mãe, um negócio de revenda deroupas. Em 2001, aos 17 anos, conseguiu, por meio da indicação de uma amiga, emprego como atendente na Companhia Atlética, no Shopping M orumbi: lugar de ricos e famosos em busca de "saúde e boa forma". Para ela, a boa sorte chegou. É de lá que N air esperaalçar vôo e conseguir em regos mais promi ssoresnas lojas desse luminoso circuito do consumo de alta renda. N air também pensa em seu futuro: quer aprender inglês, fazer um curso deenfermagem, juntar al gum dinheiro nessa profissão, para então realizar o sonho de uma faculdade defisioterapia. Enquanto espera a boa sorte, $\mathrm{N}$ air acompanha o primo $\mathrm{M}$ aurício em suas andanças pela cidade, entre shoppings centers e bares de $\mathrm{V}$ ila $\mathrm{M}$ adalena, PinheiroseM oema.

O s dois primos têm em mira outros horizontes. M aurício empenha-se em melhorar de vida: completou o segundo grau e quer continuar os estudos, nunca vacilou na procura do emprego e tenta tirar tudo de si para encontrar um lugar melhor. Enfim, M aurício é um empreendedor, como sua prima $N$ air. É assim que ele se enxerga, e ela também. E, para ambos, é esse 0 crivo que faz a diferença com relação a seus amigos de infância e vizinhos. "Também tem gente como eu", diz M aurício, "gentequebatal hae quer mudar de vida." M as avalia: "A maioria fica onde está, vai se acomodando, não quer saber de nada, não tenta outros vôos para suas vidas". Essa é uma clivagem complicada, bem sabemos. 0 ethos empreendedor do individualismo mercantil está aí bem cifrado, também o sabemos. M as é nesse código que ele formula as esperanças de construir uma vida plausível. É nessa clivagem que está o nervo (um deles) exposto do mundo. 0 problema não émorar na favela. São mundos diferentes, mas o domínio dos dois códigos não é excludente, e eles transitam entre um e outro com desenvoltura.

$M$ aurício e sua prima $N$ air são personagens que esclarecem al go sobre 0 modo como a dobradura entre os mundos é feita, entre a materialidade da cidadee seus circuitos ea natureza das conexões (e dos conectores) que ope ram esse jogo de acessos e bloqueios. É aí, nessas dobraduras da vida social, queo dramaseconfigura. Por isso mesmo os percursos dessesjovens personagens nos ajudam a compor o quadro das complicações atuais: o mundo dos serviçoseseuscircuitosmodernos, verdadeiro campo degravitação (referências, possibilidades e também bloqueios) em um cenário de encolhimento dosempregosedetrabalho precário. $E$ ainda: aviolênciadetodososdiaseos "caminhostortos" davidaquevão capturando muitos deseus vizinhos (como 
em todos os lugares) nos circuitos do tráfico de drogas e da criminalidade violenta. Tudo isso compõeum conjunto de coordenadasqueajudam adese nhar uma cartografia social, seguindo as linhas de força que atravessam 0 mundo social eseus pontos de ruptura, suas passagens etambém suasambivalências.

\section{Jorge, 0 trabalhador precário: no circuito fechado das agências de trabalho temporário}

Os percursos desses jovens encantados com os circuitos faiscantes da "cidade global" têm que ser confrontados com outros, com os daqueles que transitam nos circuitos que se alimentam da riqueza da cidade global, sem conseguir romper o círculo de ferro das agências de trabalho temporário. Assim éa história de Jorge, 31 anos, o filho mais novo do patriarca $G$ enésio e tio, portanto, dos jovens empreendedores.

0 rapaz tem uma história em tudo diferente dos irmãos mais velhos. Entrou na vida adulta em um mundo já revirado, não encontra alternativas fora do trabalho precário e amarga períodos prolongados de desemprego. Impossível reproduzir a estável trajetória de trabalho de seus irmãos. M as ele viveu a virada dos tempos também pelo outro lado, o da violência, que em poucos anos dizimou quase todos os seus amigos de infância e adolescência. E liquidou um animadíssimo grupo de som que ele comandava junto com amigos, abastecido com CD s e discos comprados nas famosas galerias do $C$ entro da cidade, ponto de encontro de jovens aficionados do rap e do hip-hop. Como ele conta, al guns foram mortos, outros estão fugidos. Ele também "contrariou a estatística", para evocar o trecho de uma letra de música dos Racionais $M C$ s, grupo de rap que é uma referência importante nas periferias da cidade e certamente um pólo de identificação para J orge, como para tantos outros (cf. K hel, 2000). D iferente dos sobrinhos empreendedores, as luzes faiscantes dos serviços globalizados não fazem parte de suas cogitações, e ele tampouco sonha em morar em outras paragens. É lá mesmo, na periferia (é ele que usa o termo, "é tudo periferia"), que constrói conexões de sentido de sua vida. Como ele diz, "periferia é isso aí... aquela música dos Racionais diz tudo".

J orgetem uma trajetória ocupacional errática, não consegueseestabelecer nos empregos e vai seguindo os anos entre períodos de trabalho precário e desemprego. 0 único traço decontinuidadeem sua história ocupacional éa intermediação das agências de emprego temporário, e o único traço em co- 
mum com seusirmãos maisvelhoséa circulação pelo quepoderíamos chamar demercado local. M assepara esteso raio decircunferência dosempregosfoi em grande parte demarcado pelas redes sociais em que circulavam informações eaberturas deoportunidades, no caso de J orge os tempos são outros ea entrada no mercado se faz em boa medida pela intermediação das agências. São elas que arbitram e decidem a locação dos empregados, e as escalas de distância e proximidade é justamente um dos critérios. $\mathrm{N}$ ão poucas vezes $M$ aurício viu suachance deemprego seesvanecer por não morar nasproximidades da empresa.

É verdade queal guns furam o cerco e conseguem emprego. M as entram então em um circuito fechado, muito difícil deser rompido. Assim acontece com M arcelo, 22 anos, que mora em um bairro ao lado. Tem o secundário completo, fez curso de informática e outro com o indefinível nome de "técnicas comerciais". Conseguiu um emprego de caixa no Carrefour. Trabalho temporário. Atéque se saiu bem e conseguiu ser contratado. $M$ as, ele pondera, caixa de supermercado não éfuturo nem dá futuro para ninguém. No máximo, de caixa a repositor de estoques. $M$ arcelo espera mais da vida. Contudo, ele diz que, uma vez em supermercado, sempre em supermercado - "no que você coloca a experiência de supermercado no currículo, um American Express, uma Xerox, uma firma não vai te chamar, o cara da empresa vai te olhar e vai falar, o cara é supermercado, vai trabalhar em supermercado". Saiu desse emprego e tentou outras entradas no mercado de trabalho: apelou a amigos e conhecidos, espalhou currículos por todos os cantos. Sem sucesso. D epois de algum tempo, foi chamado para trabaIhar no hipermercado Extra. "C aí na real", diz M arcelo, "não tem jeito", ou isso ou o desemprego. Q uando o encontramos, em 2001, havia sido promovido a repositor de estoques.

\section{Arnaldo, o motoqueiro: nos limiares do legal e ilegal}

Seas agências de trabalho temporário parecem circunscrever um estreito perímetro da experiência social, nos percursos de um motoboy outras facetas desse mundo urbano vão se perfilando nosterritórios por ondeesses rapazes circulam. 0 fato éque nessa região que se espal ha às margens do quadrante globalizado dacidade, os motoqueiros compõem a pai sagem urbana efazem ver os pontos de combustão desse entramado de relações, urdido nas "ligações perigosas" desses fluxos de riqueza e de pobreza que se tangenciam ese entrecruzam o tempo todo. É possível encontrá-los em bandos circulando 
pelas ruas e avenidas que cortam a região. $\mathrm{N}$ avegam nas ondas dos serviços terceirizadosquesevão espal hando por todosos lados equeatendem os luminosos circuitos da riqueza globalizada. Como diz um jovem motoqueiro, "quem tem moto estácom afacaeo queijo na mão". Com amoto, diz ele, são maiores as oportunidades (oportunidades?) de ser chamado por alguma agência de emprego ou de serviços terceirizados para cobrir a demanda das empresas que circundam a região. $E$, enquanto a boa sorte não aparece, eles vão sevirando como podem, nem queseja parafazer um bico ou outro como entregador de pizza.

Essa éa história deArnaldo, 22 anos, secundário completo. Eleéfilho de um ex-metalúrgico, que, nos agitados anos da década de 1980, esteve na linha de frentedas mobilizações operárias do período eigualmentese envolveu em um muito ativo e organizado movimento de moradia no bairro em queentão recém seinstalaracom afamília. Arnaldo bem quetentou seguir o exemplo do pai e conseguir um emprego industrial. M as os tempos já são outrose, de demissão em demissão, tenta se virar como podefazen do uso de sua moto: o rapazéum motoboy. H ouveum tempo em queArnaldo acreditava quea moto haveria deabrir as portas do mercado detrabal ho. $N$ ão deu muito certo. Em 1998, começou a trabal har demotoboy em uma empresa terceirizada que presta serviços para a Sabesp: entregar aviso de atraso de pagamento das contas de água - "você vai na casa da pessoa, a pessoa tem três contas atrasadas e você vai lá entregar o aviso de corte - a pessoa tem uma semana para pagar, senão pagar vai outra pessoa lá, fecha o registro elacra o registro". Ficou apenasum ano esaiu em 1999, porqueera muito perigoso, além denão ter carteira assinada e tampouco oferecer alternativas promissoras. A descrição de Arnaldo é precisa: sem registrar em carteira, a única "garantia" é um convênio com uma oficina de peças: "[...] sea moto quebra, vai lá, pegaa peça e paga no outro mês [...] não tem registro em carteira e, se tem acidente, aí vocêficaferrado".

Além do risco de acidentes de trânsito, o perigo maior está na própria natureza do serviço. Ele tinha que circular nas regiões onde as pessoas não pagam as contas de água, ou seja, nos recônditos mais pobres da periferia da cidade. E não poucas vezes, nesse percurso, o motoqueiro voltava a pé, sem a moto:

\footnotetext{
[...] era muito perigoso... trabal hava com moto, ia em muita periferia... tem um vizinho quetrabal halá, já roubaram a moto dele[...] tenho dois colegasque trabal havam lá, os doisjá perderam moto... émais periferia, favela, pro lado do C apão, tudo área perigosa.
} 
ParqueSanto Antônio, Jangadeiro, C apão, Jacira... o pior lugar era o Jacira... esse colega meu roubaram a moto lá no Jacira.

Perspectivas de futuro? N enhuma, diz Arnaldo, com firmeza: étrabalho para os quejá não conseguem mesmo outra coisa na vida: "a maioria écara que já teve passagem na polícia, não consegue outro emprego, edaí tem que apelar para isso aí. É cara quejá foi preso... não dáfuturo, não dá nada, acho quenão".

0 trajeto de um motoqueiro é mais do que eloqüente para se pensar 0 modo como a experiência do trabalho abre-se ou desenrola-se nas múltiplas facetas da experiência urbana. É como se esse trajeto também fosse percorrendo a linha de intensidade que atravessa os vários mundos sociais que se sobrepõem e compõem a realidade urbana: a empresa pública de saneamento urbano, as novas formas de gestão e as práticas da tercei rização, os insolváveis em tempos de "verdade tarifária" imposta pela lógica triunfante do mercado, a pobreza da periferia, emaisa legião dos queforam pegos pela "maldição do destino" e não mais conseguem emprego em canto nenhum, tudo isso misturado com as energias mobilizadas por esse objeto do desejo que são as motos e quetambém vão constelando referênciasimportantesna sociabilidade cotidiana dos jovens nessa região.

M as as histórias que circulam são também muito confusas, tão confusas queparecem dar plausibilidadeaos rumores esuspeitas dequeas empresas de motoboys (assim como os perueiros) são hoje "frente deinvestimento" do dinheiro sujo. E, ao que parece, essas empresas estão se proliferando nessa região situada nas franjas da "cidadeglobal".

A história de Fernanda, 20 anos, vizinha de Arnaldo, no mesmo bairro, diz alguma coisa a esse respeito. Seu irmão arriscou abrir uma empresa de motoboys. $\mathrm{N}$ ão foi bem-sucedido e em pouco tempo estava enterrado em dívidas. M as a garota ajudava o irmão e "ganhou experiência", como se diz. D epois, a sorte a levou a um escritório imobiliário no Centro Empresarial, portal da "cidade global", enclave globalizado incrustado nas imediações, assinalando os limiares de dois mundos contrastados. Era secretária, e sua tarefa eralidar com as empresas de motoboy. Saiu-setão bem quefoi chamada por um motoboy bem-sucedido, quequeria montar uma empresa própria em Itapecerica da Serra, município da G rande São Paulo contíguo à periferia sul da cidade e não muito distante dessa região. 0 rapaz trabalhava em uma empresa que "era bem falada, eu conhecia a maioria dos funcionários, elesiam direto falar comigo... aí eu falei 'tudo bem'". D aí para frenteéuma 
sucessão de promessas não cumpridas, pagamentos não efetuados, cobranças de dívidas atrasadas, enquanto o dinheiro sumia por meandros inexplicados (inexplicáveis, talvez). É uma história muito confusa. Fernanda conta que os planos não eram modestos: montar a parte operacional em São PauIo, com motoboys, perua e ônibus. E, em Itapecerica, o plano era montar pacotes turísticos para as escolas. 0 rapaz falava em promover excursões até Barretos, no interior de São Paulo. Fernanda logo se pôs a campo e pediu para o irmão providenciar o material gráfico necessário para a divul gação cartazes, cartões de visita, envelopes com logotipo. N esse meio-tempo, a família toda deFernanda já estava envolvida no negócio. A mãefoi chamada para fazer a faxina do escritório, a irmã foi contratada como secretária e havia ainda uma amiga do bairro que ajudava nos serviços internos. $\mathrm{N}$ inguém recebeu pagamento. 0 s motoqueiros, mais de vinte, tampouco.

A garota tem secundário completo e é muito empreendedora. Além do mais, tem umafamília muito articulada, mora em um bairro com uma malha de relações sociais superdensa, tudo muito organizado, ativo esolidário. Em uma palavra: éuma garota portadora, como sediz, de um vasto capital social. A final, foi assim queconseguiu o emprego quepoucos conseguem, no C entro Empresarial deSão Paulo. Apesar da poucaidade, atrajetória ocupacional de Fernanda énotável, uma sucessão razoável de empregos, todos eles obtidos por meio da trama de relações em que circulam informações eas "boas recomendações". M as é uma trajetória notável também pela instabilidade evulnerabilidade, semprenasfronteiras entreo mercado formal einformal - várias arbitrariedades, demissões sucessivas, salários atrasados, direitos desrespeitados. Enfim, nadaa estranhar: redesecapital social não deixam de repor as circunstâncias decircuitosem pobrecidos de uma região igualmente empobrecida equeacionam empregos precários deum mercado detrabalho, com o perdão da tautologia, precarizado. M as a empreendedora Fernanda bem quechegou perto deescapar das tramas da precariedadequando, mobilizando seu capital social, conseguiu o promissor emprego no C entro Empresarial, o mesmo capital social que o rapaz da empresa de motoboy tratou de mobilizar para o seu fraudulento negócio. Em pouco tempo, a única coisa queesse capital social acumulado Iherendeu foram muitas dívidas (contas de telefoneeágua atrasadas em razão de um salário quenunca foi pago) ecompromissos não respeitados (o irmão empenhou o próprio nome para conseguir a impressão dos cartazes, e a conta também ficou para ser paga algum dia), além de muitos sustos, o pior deles quando um "cliente" encolerizado apareceu no escritório para cobrar a "sua parte", dearma na mão, impropérios 
na boca eameaças debarbarizar o local. M aso moço das motosa essas alturas já tinha sumido com os dividendos expropriados do capital social al heio, e ninguém sabia por ondeeleandava.

Fernanda e o motoqueiro Arnaldo moram em um bairro que poderia constar do rol dos casos exemplares de capital social eredes sociais atuantes. M as, como diz Bruno Latour (2000), se o assunto são as redes, é preciso considerar que elas "são mais ou menos longas, mais ou menos conectadas", e também envolvem "boas conexões" e "más conexões". Q uer dizer: o problema todo está em saber e compreender o modo como os vínculos operam, já que, sempre situados e sempre territorializados, eles se fazem na composição ena conjugação entre circunstâncias, fatos, coisas eatores. São nesses pontos de junção e conexão da vida social que se torna perceptível a pulsação do mundo urbano. E é justamente isso que o trabalho (e a experiência do trabalho) permite apreender.

\section{Geraldo, o segurança: nos circuitos da segurança privada, em que todos os fios se cruzam}

G eraldo, 27 anos, ésegurança em um hotel cinco estrelasna avenida Luiz C arlosBerrini, coração globalizado da cidade, pólo deirradiação do chamado terciário moderno de última geração. Vizinho do patriarca Genésio e sua extensa família, G eraldo étambém filho deum operário metalúrgico quefez o percurso por uma das grandes indústrias queantes pontilhavam na região. D emitido no final dosanos de 1980, a partir daí seus expedientes desobrevivência são um tanto obscuros, entre as malhas do clientelismo político e os chamados negóciosilícitos. Foi assim que conseguiu agenciar boa parte das melhorias urbanas locais eé por essas vias queexerce poder einfluência nos assuntos elitígios que ocupam eagitam os moradores.

Se o pai se deixou envolver na vida local da favela, entre expedientes obscuros de sobrevivência e as mal has do clientelismo local ao velho estilo, G eraldo sabe muito bem fazer as passagens entre esse mundo e os modernos circuitos da "cidade global". C omeçou a trabalhar aos 19 anos. TrabaIhou como garçom em um flat em M oema, onde ficou apenas três meses. D epois trabalhou por um ano em uma das pequenas fábricas ao lado da favela. Por intermédio de um amigo, conseguiu emprego de fiscal em lojas e circulou em al gumas das importantes lojas de departamento e shoppings centers da cidade. $M$ as era um trabal ho instável e $G$ eral do não conseguia se fixar em canto nenhum. A grande virada de sua vida foi o curso de seguran- 
ça que fez em 1997. Ele mudou de patamar: entrou no ramo nobre da segurança privada. A pesar de ser um emprego muito instável (está sujeito a todas as inseguranças e também irregularidades das redes de subcontratação), G eraldo está encontrando aí uma chance de escapar da "viração" de todos os dias de muitos de seus vizinhos. E o trabalho o lança nos luminosos circuitos dos serviços modernos.

Como pudemos flagrar em outros lugares, o emprego de segurança é hoje visto como muito promissor. Como nos disse um jovem que mora em um bairro vizinho, também pauperizado e muito mal-afamado por seus altíssimos índices de morte violenta, é "um emprego certo, tem mercado garantido". Sival do, 28 anos, também fez um curso de segurança credenciado e regulado pela Polícia Federal. Já trabal hou em agências de al guns dos mais importantes bancos brasileiros e em lojas dos mais sofisticados shoppings centers do rico e globalizado quadrante sudoeste da cidade. Trabal ha agora em uma empresa que presta serviços em bingos e casas noturnas. Sivaldo não soube explicar muito bem o estatuto dessa empresa, para ele é pouco claro o modo como os serviços são contratados e remunerados. M uito provavelmente a empresa compõe esse universo amplo etambém expansivo, se não dos serviços clandestinos, dos que transitam nas frontei ras pouco claras do legal eilegal, por conta de expedientes diversos para escapar das regulações oficiais que vigoram nos serviços de segurança (cf. Caldeira, 2000).

Sivaldo começou a trabalhar muito cedo, aos 14 anos. Já foi officeboy, ajudante em barraca defeira enos mercadinhos locais, coletor delixo, trabaIhou em lava-rápido, montou junto com amigos um bar e depois uma barraca de pastel. Foi também cobrador em peruas clandestinas - foi um bico, diz ele, quearrumou com os amigos perueiros, seus vizinhos no bairro onde mora. $\mathrm{N}$ ão ficou muito tempo. A perua em que trabalhava foi assaltada, achou que o trabal ho era muito perigoso equeria coisa melhor. Tinha então 23 anos e vendeu seu carro para pagar as mensalidades do curso de segurança. É nesse ramo que pretende se fixar e progredir na vida.

Como tantos outros de sua geração, falar dos amigos éfazer a contabilidade das mortes. D os tempos de infância e adolescência, diz Sivaldo, "só salvou dois ou três". O soutros foram mortos, executados ou sumiram pelos caminhos tortos da vida. Sivaldo conhece bem as "coisas da vida" e talvez seja isso quelhe permitecerto distanciamento crítico dessa sua "promissora" atividade. É perigoso, diz Sivaldo, não apenas porque se está exposto aos riscos próprios da profissão. M as também porque "do lado de cá" a coisa não éfácil. Ele conta queémais do quefreqüente os seguranças serem pressiona- 
dos pela bandidagem: recebem ofertas de dinheiro, de proteção, e promessas de uma porcentagem no "ganho", ou então são sujeitos ao jogo pesado da pressão aberta para que forneçam o "mapa da mina". Eles querem saber todos os detal hes do modo defuncionamento do local. É assim, diz Sivaldo, a "maldição do dinheiro", pois "tem vigilanteque está precisando de dinheiro, que está desesperado, daí eles vão lá, fazem uma reunião na casa do 'grandão', ele passa tudo, eles analisam" e, então, fazem o "serviço".

$M$ as, diz Sivaldo, o esquema de segurança nos bancos, nos prédios de escritório e nos shoppings centers mais ricos e prestigiosos da cidade está mais do que sofisticado. A entrada nesses domínios está fican do muito difícil, e então os fluxos do crime organizado vêm se deslocando para os lados da periferia pobre da cidade: caixas eletrônicos, supermercados, comércio local ou bingos e casas noturnas que se espal ham pelas avenidas que cortam esses pedaços periféricos da cidade. Sivaldo sabeo que está fal ando: " $Q$ uem conhece, quem nasceu e cresceu na periferia, sabequeno final do ano são os alvos do crime organizado, para passar um final de ano bom, né?... Se eles estiverem lá dentro, não há como reagir, é só pegar e pedir a D eus...".

O s seguranças privados são personagens inescapáveis da "cidade dos muros" e fazem parte dos dispositivos de privatização dos espaços públicos (e da cidade), ao mesmo tempo em que são mobilizados em um mercado expansivo, também globalizado, que faz da segurança uma mercadoria vendida sob formas cada vez mais sofisticadas e variadas (cf. Caldeira, 2000). Em torno deles, todos os fios se cruzam: o mercado, as fortalezas globalizadas da cidade e os circuitos faiscantes dos modernos equipamentos de consumo. $M$ as também o seu transbordamento para as periferias da cidade: 0 moderno-moderníssimo trabal ho precário, as redes de subcontratação eessa mistura ou indiferenciação entre formal e informal, legal e ilegal, que vai seguindo as linhas que fazem as tramas da cidade.

0 que esses personagens (etambém os anteriores) nosfazem ver em seus percursos é que essas linhas perpassam as fortal ezas globalizadas da cidade, transbordam seus muros ou vazam pelos poros dessas mural has, e tal como outros tantosfluxos urbanos vão também redesenhando os territóriose seus circuitos. M odo muito peculiar pelo qual se estabelece a relação entre trabalho e cidade pelas vias de uma cadeia de mediações e conexões na qual estão cifradas todas as facetas do mundo urbano atual. N ão precisamos 
lançar mão de nenhum argumento miserabilista, nem denunciar a fome do mundo para ter a medida da tragédia social que está aí cifrada.

M as isso ainda abre outra questão: afinal, onde situar cada um desses personagens? São pobres infelizes da sorte? Excluídos? Senão, faz al gum sentido dizer que são, então, "incluídos"? São personagens que fazem os seus percursos nas tramas do mundo social. Essas categorias (e binaridades) tornam-se estreitas demais para colocar em perspectiva as questões que essas históriasnosabrem. 0 scampos deforçae todaa complicação dostemposque correm estão exatamente nos pontos de conexão dessas tramas que fazem a tapeçaria do mundo social.

Esses personagens escapam às categorias habituais que pautam os debates recentes. $\mathrm{N}$ ão correspondem às figuras canônicas do trabalhador regular, tampouco às do mercado informal, e muito menos às tipificações correntes dos "pobres" e "excluídos", público-alvo dos programas ditos de inserção social. N o entanto, seus percursosfazem ver ateia derelaçõese campos deforça queseestruturam em torno do trabalho, mas queseesvanecem sob ostermos correntes do debate atual.

É justamente isso que está a exigir que se relance a pergunta sobre os sentidos do trabal ho e seus efeitos estruturantes na vida social. Retomando questões do início desteartigo, talvez seja preciso então um deslocamento do jogo de referências para ressituar o trabalho no mundo social. Se não mais vigoram as regulações conhecidas do emprego e o feixe de suas mediações políticas e institucionais, então talvez seja o caso de prospectar os vetores horizontal izados que articulam o trabal ho, a cidade e seus espaços. 0 utros agenciamentos entreos tempos davida eostempos do trabal ho. 0 utras referências também pelas quais a experiência das desigual dades vem se processando. Se ela não é mais remetida às configurações de classe, talvez esteja sendo configurada nos espaços da cidade eseus circuitos.

M as, então, será preciso indagar sobreos campos de experiência em suas novas configurações, não maisas "relações declasse" deantes, mas aquelas que ganham forma e pulsam nas situações descritas aqui, etambém nas redes de subcontratação eseus intermediários, no trabalho a domicílio que mobiliza relações de proximidadeentrefamiliares e vizinhança, enas miríades deoutras situações detrabal ho que hoje compõem o mundo urbano.

M omento oportuno para uma releitura deT hompson (1979), para com ele aprender a escutar os rumores da cidade. $N$ ão mais os "rumores da multidão" (ou não os mesmos), com os quais o autor identificou campos de experiência e desenhou o cenário das relações conflitivas e as resistências 
surdas ou manifestas da Inglaterra do século XVIII. M esmo quando não ganham superfície, mesmo quando socialmente invisíveis, resistências não deixam de existir como um surdo rumor crítico em busca de referências, mediadores e meios de expressão (cf. Telles e C abanes, 2006).

\section{Referências Bibliográficas}

Aspe, Bernard; Com Pes, M uriel \& Lazzarato, M aurizio. (1996). “Letravail: un nouveau débat por de vieilles al ternatives". Futur Antéri eur, 35-36, Paris, sitewww.multitudes. samizdat.net, consultado em 04/02/2006.

Beaud, Stéphane\& Pialoux, M ichel. (2003), Violencesurbaines, violencesociale genèsedes nouvellesdasses dangereuses Paris, Fayard.

BEssin, M arc. (1999), "Lestemps, une question de pouvoir". M ouvements, 2: 47-54, jan.fev., Paris.

CALDEIRA, Teresa. (2000), A cidadedos muros violência, segregação ecidadania na cidadede São Paulo. São Paulo, Editora 34.

D eleuze, Gilles. (1992), "Post-scriptum sobre as sociedades de controle". In: Conversações. São Paulo, Editora 34, pp. 219-226.

Eh EREM Berg, Alain. (1991), Lecultedela performance. Paris, H achette Littératures.

H ARVEY, D avid. (1996), “D o gerenciamento ao empresariamento: a tranforformação da administração urbana no capitalismo tardio". Espaço eD ebates, 39: 121-145, São Paulo.

KHEL, M aria Rita. (2000), Função fraterna. Rio de aneiro, Relume-D umará.

KURz, Robert. (1992), 0 colapso da modernização. Rio deJaneiro, Paz eTerra.

Latour, Bruno. (2000), "Faktura: de la notion de réseaux à celle d'attachement". In: M Icoud, André\& Peron I, M ichel. Cequi nousrelie. Paris, Éditionsdel'Aube, LaTour d'Aigues, pp. 189-208.

Lazzarato, M aurizio (2002). "Leconcept detravail immatériel: lagrandeentreprise”. Futur Antérieur, 10. Paris, stewww.multitudes.samizdat.net, consultado em 05/05/2005.

Le M ARCHANd, Arnaud. (2004). "Travail intermittent et production delavillepost-fordiste". M ultitude, 17. Paris, site www.multitudes.samizdat.net, consultado em 04/02/2006.

O liveIRA, Francisco de. (2003), "O ornitorrico". In: . Crítica à razão dualista. 0 ornitorrinco. São Paulo, Boitempo, pp. 121-150.

SASSEN, Saskia. (1998), Ascidadesna economia global. São Paulo, N obel.

Sennet, Richard. (2000), A corrosão do caráter. Rio de Janeiro, Record.

SupI0t, Alain. (1994), Critiquedu droit du travail. Paris, PU F. . (1999), Au-delà del'emploi: transformationsdu travail et devenir du droit du travail en Europe. Paris, Flamarion.

Telles, VeraS. (2006), “Trajetórias urbanas: fios deuma descrição da cidade”. In: Telles, 
VeraS. \& C ABAn ES, Robert (orgs.). N astramasda cidade trajetóriasurbanaseseuspersonagens. São Paulo, H umanitas (no prelo).

Telles, VeraS. \& CABAn Es, Robert (orgs). (2006), N astramasda cidade trajetóriasurbanaseseuspersonagens. São Paulo, H umanitas (no prelo).

Th OM PSON, Edward. P. (1979), Tradición, revuelta, consciencia de clase estudiossobrela criśs dela sociedad preindustrial. Barcelona, $C$ rítica.

V eltz, Pierre. (1996), M ondialisation, villeset territoires. l'économied'archipel. Paris, PU F. Zaluar, Alba. (1996), "A globalização do crime os limites da explicação local". In: VELHo, G ilberto \& A Avito, M arcos(orgs.). Cidadania eviolência. Rio dejaneiro, Editora daFGV/Editora daU FRJ, pp. 48-68.

Zarifian, Philippe. (2000), “Engajamento, disciplina econtrole”. N ovosEstudos. 64: 2333, nov., São Paulo.

. (2003), "La disparition du marché". In: ZARIFIAN, Philippe. A quoi sert letravail?

Paris, LaD ispute, pp. 135-147.

\section{Resumo}

Mutações do trabalho e experiência urbana

N esteartigo, pergunta-se sobreas dimensões societárias das atuais mutações do trabal ho, em particular sua desconexão dos dispositivos do emprego sob as formas variadas detrabaIho precário edesubcontratação, ou seja: dequemodo as novas realidades do trabal ho (edo não-trabalho) redesenham o mundo social, as relações deforça eos campos de práticasque fazem a tessitura da cidadee seus espaços. Ascircunstâncias do trabal ho precário eintermitente alteram tempos e espaços da experiência social, bem como a própria experiência urbana nos circuitos descentrados dos "territórios da precariedade". Esteartigo propõe prospectar essas novas real idades seguindo os percursos eas traj etórias urbanas das novas gerações. Acredita-se que essa pode ser uma via deentrada profícua para a descrição desse mundo social redefinido: a diferença entreas geraçõestem hojea peculiaridadehistórica de coincidir com mudanças de fundo no mundo do trabal ho enas dinâmicas urbanas. Por outro lado, essa é também uma maneira de relançar a pergunta sobre os sentidos do trabal ho eseus efeitos estruturantes na vida social.

Palavras-chave: M utações do trabal ho; Reconfigurações urbanas; D iferença de gerações; Práticas sociais; Experiência social.

\section{Abstract}

Mutations of work and urban experience

This articleinquires into the societal dimensions of contemporary mutations of work, in particular their disconnection from employment mechanisms through various forms of casual work and outsourcing. I n other words, it asks in what way thenew realities of work 
(and non-work) redraw the social world, the relations of forceand the fields of practices that make up the texture of the city and its spaces. The circumstances of casual and intermittent labour alter the time and space of social experience, as well as the urban experienceitself in the decentred circuits wecan denominate "territories of precariousness". Thearticle proposes to investigatethesenew realities by following the paths and urban trajectories of thenew generations. It suggests that this is a fertileentry point for describing this redefined social world: the difference between generations today has the historical peculiarity of coinciding with deep changes in theworld of work and in urban dynamics. Thisisalso a way of re-approaching the question of themeanings of work and its structuring effects on social life.

Keywords: M utations of work; U rban reconfigurations; G enerational difference; Social practices; Social experience.

Texto recebido eaprovado em 8/5/2006.

Vera da Silva Telles é professora do D epartamento deSociologiada U niversidade de São Paulo epesquisadora do Centro deEstudos dos D ireitos da Cidadania, Cenedic (USP). E-mail: tellesvs@uol.com.br. 